Шульгина И. А., Шунейко А.А.

ХАРАКТЕРИСТИКА ИНТЕРНЕТ-РЕСУРСОВ В ИНФОРМАЦИОННОМ ПРОСТРАНСТВЕ ХАБАРОВСКОГО КРАЯ

Шульгина И. А., Шунейко А. А.

I. A. Shulgina, A. A. Shuneyko

ХАРАКТЕРИСТИКА ИНТЕРНЕТ-РЕСУРСОВ В ИНФОРМАЦИОННОМ ПРОСТРАНСТВЕ ХАБАРОВСКОГО КРАЯ

\title{
DESCRIPTION OF INTERNET RESOURCES IN THE KHABAROVSK TERRITORY INFORMATION SPACE
}

Шульгина Илона Александровна - студентка кафедры лингвистики и межкультурной коммуникации Комсомольского-на-Амуре государственного технического университета (Россия, Комсомольск-на-Амуре); 681000, г. Комсомольск-на-Амуре, ул. Ленина, 27. E-mail: shulgina.il.al@gmail.com.

Ms. Ilona A. Shulgina - a student, Linguistic and Cross-cultural communication Department, the Komsomolskon-Amur state technical university (Russia, Komsomolsk-on-Amur); 27, Lenina Str., Komsomolsk-on-Amur. E-mail: shulgina.il.al@gmail.com.

Шунейко Александр Альфредович - доктор филологических наук, доцент, профессор кафедры лингвистики и межкультурной коммуникации Комсомольского-на-Амуре государственного технического университета (Россия, г. Комсомольск-на-Амуре); 681013, Комсомольск-на-Амуре, пр. Ленина, 27; 8-421752-98-18. E-mail: shuneyko@knastu.ru.

Mr. Alexander A. Shuneyko - Dr. of Philology, Associate Professor, Professor, Linguistics and Cross-cultural Communication Department, Komsomolsk-on-Amur State Technical University (Russia, Komsomolsk-on-Amur); 681013, Komsomolsk-on-Amur, 27 Lenin St.; 74217 529818. E-mail: shuneyko@knastu.ru.

Аннотация. В статье рассматривается Интернет-пространство Хабаровского края, приводится тематическая классификация Интернет-ресурсов, ориентированных на жителей края, и осуществляется контент-анализ пяти информационных порталов. По результатам исследования приводится процентное соотношение тем публикаций на каждом из ресурсов, выделяются наиболее и наименее популярные темы. Наиболее популярными являются темы из разделов «Социальная сфера» и «Культура». Наименее популярными являются темы из разделов «Религия» и «Статистика». Делаются выводы о специфики размещения публикаций на каждом портале. Для сайта с самой высокой частотой обновления характерно большое количество публикаций из раздела «Криминальная хроника». Сайты, являющиеся электронными вариантами печатных изданий, большее внимание уделяют разделам «Социальная сфера», «Культура» и «Спорт». Наименьшее количество публикаций на этих ресурсах приходится на разделы «Образование и наука», «Статистика» и «Религия».

Summary. The article discusses the Internet space of the Khabarovsk territory, a thematic classification of Internet resources, which are interested to region's inhabitants. Content analysis of five information portals is conducted. According to the results of the research, the percentage of publications on each of the resources is given; the most and least popular topics are selected. The most popular topics are from the sections "Social sphere" and "Culture". The least popular are the topics from the sections "Religion" and "Statistics". Conclusions are drawn about the specifics of the publication of publications on each portal. For a site with the highest refresh rate, a large number of publications from the "Criminal Chronicle" section are characteristic. Sites that are electronic versions of printed publications pay more attention to the sections "Social sphere", "Culture" and "Sport". The least amount of publications on these resources falls on the sections "Education and Science", "Statistics" and "Religion".

Ключевые слова: информационное пространство, Интернет-ресурсы, информация, тематические группы, Хабаровский край.

Key words: information space, Internet resources, information, thematic groups, Khabarovsk territory. 
УДК 13.11.25

Исследование проведено при поддержке Правительства Хабаровского края. Договор № 192/2017 Д от 19.06.17 о предоставлении гранта на проведение научных исследований в области гуманитарных и общественных наук.

Одним из источников пополнения информационного пространства Хабаровского края является Интернет [1]. Совокупность Интернет-страниц (сайтов) называется Интернетпространством. Существует множество исследований, в которых Интернет-пространство рассматривается как фактор формирования сетевого сообщества (Саенко и Егоров, 2015); как фактор модернизации институтов гражданского общества (Белянцев и Лымар, 2012). Изучены позитивные и критические факторы использования Интернет-пространства как базы коммуникаций в учебно-воспитательном процессе образовательной организации (Левина и Белашова, 2011). Кроме того, существует ряд исследований, в которых Интернет-пространство рассматривается как отдельный социальный институт (Хлипун, 2011; Иванченко, 2009). Однако ранее не предпринимались попытки исследования Интернет-пространства конкретного региона.

Определим Интернет-пространство Хабаровского края как совокупность Интернет-страниц (сайтов), ориентированных на жителей Хабаровского края. При этом сервера, на которых физически хранятся сайты, территориально могут быть расположены за пределами Хабаровского края. В связи с этим необходимо найти способ отбора актуальных для жителей рассматриваемого региона Интернет-ресурсов.

В настоящее время широкое распространение получили три способа поиска информации в сети Интернет: поиск по адресу, поиск с помощью навигации и поиск с использованием поисковых серверов. Поиск по адресу применяется тогда, когда известен адрес информационного ресурса. При организации поиска необходимо ввести адрес нужного ресурса в соответствующее поле браузера - программы, предназначенной для обеспечения доступа к сетевым ресурсам. Поиск с помощью навигации предполагает переход по гиперссылкам, расположенным внутри страницы. Поиск с помощью поисковых серверов - поиск с помощью специальных поисковых систем (поисковых машин). Данный вид поиска осуществляется с помощью поисковых запросов по ключевым словам. Он позволяет отобрать наибольше количество ресурсов и является самым универсальным.

Так как изначально полные адреса сайтов неизвестны, невозможно использовать первые два вида поиска. Поиск будет осуществляться с помощью поисковых средств. Данный вид поиска также называют контекстным, и он имеет ряд недостатков, связанных с тем, что полученные результаты включают в себя все сайты, на которых встречается слово или сочетание слов из поискового запроса [2]. Однако в данном исследовании для анализа необходимы абсолютно все ресурсы, удовлетворяющие поисковому запросу. Стоит отметить, что большинство популярных поисковых систем используют в своей работе ориентацию на личные предпочтения пользователя: пользователь видит только те результаты, которые согласуются с его предпочтениями. Ориентация результатов поиска на предыдущую активность пользователя в сети называется «пузырем фильтров» [3]. Для того чтобы этого избежать, будем использовать поисковую систему DuckDuckGo, которая позволяет сформировать объективную выборку результатов, не учитывая прошлое поведение в сети.

В качестве поисковых запросов были использованы названия всех населенных пунктов Хабаровского края. После анализа результатов поиска все найденные страницы были распределены по группам в зависимости от тематической направленности ресурсов. Был получен следующий список категорий Интернет-страниц: сайты органов местного самоуправления (1); новостные порталы (2); сайты развлекательных учреждений (кинотеатры, клубы) (3); доски объявлений (4); сайты вокзалов и аэропортов (5); сайты магазинов и коммерческих организаций (6); сайты гостиниц, отелей, хостелов (7); тематические группы в социальных сетях (8); сайты транспортных компаний (9); сайты спортивных учреждений (фитнес-центры, танцевальные студии, бассейны) (10); сайты газет и журналов (11); сайты туристических агентств (12); сайты 
Шульгина И. А., Шунейко А.А.

ХАРАКТЕРИСТИКА ИНТЕРНЕТ-РЕСУРСОВ В ИНФОРМАЦИОННОМ ПРОСТРАНСТВЕ ХАБАРОВСКОГО КРАЯ

консульств и посольств (13); сайты учреждений общественного питания (14); заказ продукции на дом (еда, цветы, алкоголь) онлайн (15); сайты спортивных команд (16); онлайн магазины (17); сайты учреждений здравоохранения (18); сайты риэлтерских агентств (19); сайты банков (20); сайты поставщиков специального оборудования (21); сайты театров (22); сайты салонов красоты, парикмахерских (23); сайты правоохранительных органов (24); сайты компаний по оказанию услуг населению (25); сайты центров нетрадиционной медицины (26); сайты центра космической связи (27); сайты знакомств, поиска попутчиков, аренда жилья без посредников (28); сайты образовательных учреждений (29); сайты учреждений дополнительного образования (дворцы творчества, художественные и музыкальные школы, центры организации детского досуга) (30); сайты загородных лагерей (31); страницы пользователей в соц. сетях (32); персональные блоги, онлайн дневники (33); сайты организаций ЖКХ (34); сайты библиотек (35); сайты строительных компаний (36); сайты телерадиокомпаний (37); сайты интернет-провайдеров (38); сайты церквей и религиозных организаций (39); справочно-информационные сайты (40); тематические форумы (41); сайты заводов, фабрик (42); сайты детских домов (43).

Все категории сайтов содержат разнообразную информацию, которую можно сгруппировать следующим образом: новости, обзоры, анонсы актуальных событий городского и краевого уровней $(1,2,8,11,33,37)$; проведение аукционов в отношении земельных участков и территорий (1); бюджет населенного пункта (1); услуги муниципалитета (1); размещение объявлений $(2,4,8,11,28,37,41)$; расписание движения транспортных средств $(5,40)$; информация для потребителя $(3,5,6,7,9,10,12,13,14,15,17,18,19,20,21,22,23,25,26,29,30$, $31,34,35,36,38,39,40,42,43)$; информация об организации, учредители ресурса (все категории); каталог товаров и услуг $(3,5,6,7,9,10,12,13,14,15,17,18,19,20,21,22,23,25,26,29,30,31,34$, $36,38,42,43)$; коммерческие предложения, акции, розыгрыши $(3,6,7,9,12,14,15,17,19,20,21$, $22,23,25,26,31,36,38,42)$; онлайн бронирование, электронная запись $(3,5,7,18,22,23)$; отзывы потребителей $(3,5,9,10,12,14,15,17,18,19,20,21,22,23,25,26,29,30,31,32,38,42)$; обсуждение тематической информации $(2,11,32,33,41)$; новости транспортной системы $(5,9)$; тарифы на перевозки $(5,9)$; график работы и расписание $(1,3,5,6,7,9,10,12,13,14,18,19,20$, $21,22,23,24,25,26,27,29,30,31,34,35,36,37,38,39,42,43)$; информация о персонале $(3,10,18$, $19,22,23,26,29,30)$; список достижений $(16,29,30,43)$; справочная информация $(2,5,11,13,29$, $32,33,35,37,40,41,43)$; новости учреждения $(1,3,5,6,7,9,10,12,13,14,16,18,19,20,21,22,23$, $24,25,26,27,29,30,31,34,35,36,37,38,39,42,43)$; турнирная таблица $(6,8,11,12)$; правовая информация для гражданина $(1,18,24,29)$; информация о техническом обеспечении организации $(9,18,27,29,30,38,42)$; любая информация по желанию владельца страницы $(8,32,33,41)$; электронный каталог книг (35).

То есть наибольшее количество сайтов размещают следующие материалы: информацию для потребителя (30), каталог товаров и услуг (27), коммерческие предложения, акции, розыгрыши (19), отзывы потребителей (22), график работы и расписание (31), новости учреждения (32). Для дальнейшего анализа особый интерес представляют сайты, относящиеся к следующим категориям: новостные порталы, сайты газет и журналов, персональные блоги и онлайн дневники (затрагивающие обзор событий из жизни района, города и края), потому что сайты из данной категории являются информационными сетевыми порталами и освещают актуальные для всех жителей края темы. Результаты анализа Интернет-ресурсов, входящих в рассматриваемые тематические группы, позволили выделить их основную задачу - удовлетворение информационных потребностей жителей Хабаровского края. Для этого сайты не только предоставляют информацию о деятельности органов местного самоуправления, но и предоставляют возможность комментировать и обсуждать ее, а также самим предлагать материалы для публикации.

После рассмотрения сетевого пространства Хабаровского края для анализа были выбраны наиболее крупные сетевые порталы Хабаровского края. При отборе Интернет-страниц учитывались частота обновления ресурса, территориальная направленность (отсутствие филиалов ресурса за пределами территории Хабаровского края), востребованность ресурса, возможность комментирования информации. Были выбраны следующие ресурсы: 


\section{Uิ:

- www.dvnovosti.ru (информационно-новостной ресурс Хабаровского края);

- www.komcity.ru (информационно-новостной портал, развиваемый и поддерживаемый редакцией еженедельника «Наш город»);

- ngamursk.ru (сайт городской газеты «Наш город Амурск»);

- наша-гавань.рф (информационный портал Дальневосточного побережья);

- bikinskyvestnik.wixsite.com (сайт общественно-политической районной газеты «Бикинский Вестник»).

Анализ контента ресурсов производился из публикаций в разделе «Новости», в котором размещается наиболее актуальная информация. Рассматриваемые сайты имеют разную частоту обновления материала. Сайты www.dvnovosti.ru, www.komcity.ru и наша-гавань.рф обновляются ежедневно. При этом на сайте www.dvnovosti.ru ежедневно публикуется около 20 новостей, на www.komcity.ru - около 11 и на наша-гавань.рф - около четырех новостей. Сайт ngamursk.ru является электронной версией печатного издания. Обновление информации на нем происходит раз в неделю и частично дублирует печатную версию. Pесурс bikinskyvestnik.wixsite.com также представляет собой сайт печатного издания. Обновление информации происходит раз в неделю. В связи с неравномерностью частоты обновления анализ производился по последним 500 публикациям на каждом ресурсе.

Производился анализ тем, поднимаемых в публикациях на сайтах. В табл. 1 представлены темы и их процентный объем от общего количества (500 публикаций).

Таблица 1

Процентное соотношение тем на каждом из ресурсов

\begin{tabular}{|c|c|c|c|c|c|}
\hline & $\begin{array}{l}z \\
. \\
0 \\
0 \\
0 \\
0 \\
0 \\
0 \\
0 \\
3 \\
3\end{array}$ & 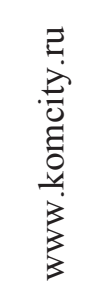 & 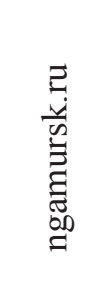 & 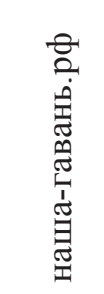 & 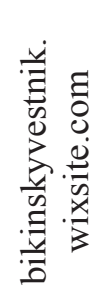 \\
\hline Социальная сфера & 21,25 & 21,8 & 43 & 25,97 & 25,35 \\
\hline Культура & 21,25 & 33,2 & 30,67 & 23,34 & 29 \\
\hline Политика & 3,75 & 2,5 & 1,33 & 13 & 9 \\
\hline Криминальная хроника & 30 & 2,5 & 1 & 3,9 & 2,33 \\
\hline Чрезвычайные происшествия & 15 & 13,75 & 1,33 & 1,3 & 0 \\
\hline Образование, наука & 2,5 & 3,75 & 4 & 1,3 & 2,33 \\
\hline Люди & 1,25 & 1,25 & 2,67 & 4 & 15 \\
\hline Экономика & 1,25 & 1,25 & 12 & 15,5 & 10 \\
\hline Спорт & 3,75 & 20 & 4 & 10,39 & 2,33 \\
\hline Религия & 0 & 0 & 0 & 1,3 & 2,33 \\
\hline Статистика & 0 & 0 & 0 & 0 & 2,33 \\
\hline Без определенной темы & 2,5 & 2,5 & 1,33 & 0 & 0 \\
\hline
\end{tabular}

Как видно из рис. 1, наиболее актуальной информацией, размещаемой на всех ресурсах, является информация из разделов «Социальная сфера» и «Культура». К разделу «Социальная сфера» отнесена информация о транспортной системе и состоянии дорог, здоровье и медицине, а также вопросы ЖКХ и строительства. В раздел «Культура» включены материалы о различных концертах и мероприятиях, торжественных награждениях, выставках, конкурсах творческой самодеятельности и т.д. Данный раздел наиболее часто пополняется в преддверии 
Шульгина И. А., Шунейко А.А.

ХАРАКТЕРИСТИКА ИНТЕРНЕТ-РЕСУРСОВ В ИНФОРМАЦИОННОМ ПРОСТРАНСТВЕ ХАБАРОВСКОГО КРАЯ

государственных и краевых праздников. Наименьшее количество публикаций приходится на сферы «Религия», «Статистика» и «Образование, наука».

Сайт www.dvnovosti.ru основное внимание уделяет публикациям материалов, относящихся К темам «Криминальная хроника», «Социальная сфера», «Культура» и «Чрезвычайные происшествия» $(30,21,21$ и $15 \%$ соответственно). К теме «Криминальная хроника» были отнесены все публикации о криминальных происшествиях на территории края. Раздел «Чрезвычайные обстоятельства и происшествия» включал в себя все публикации о пожарах, ДТП без очевидцев, трагических происшествиях, пропаже людей без вести, административных правонарушениях.

Остальные темы на сайте www.dvnovosti.ru не превышают 5 \% от общего количества рассматриваемых публикаций. Темы «Спорт» и «Политика» занимают почти 4 \%. Раздел «Политика» активно пополняется во время избирательных кампаний. Раздел «Образование, наука» включает в себя публикации о школах и вузах, а также информацию о научных достижениях и деятельности ученых Хабаровского края. Разделы «Люди» и «Экономика» занимают около 1 \%. В раздел «Люди» включены публикации об известных людях края. К теме «Экономика» отнесены статьи о налогообложении, субсидировании, пенсионных начислениях и т.д. Около $2 \%$ публикаций на сайте не относятся ни к одной из тем, и они были отнесены к разделу «Без определенной темы». Основную часть публикаций на pecypce www.dvnovosti.ru составляют сводки криминальной хроники, так как ресурс является самостоятельным и не дублирует информацию из печатных изданий. Новостная лента формируется из обзора происшествий и актуальных событий края (разделы «Социальная сфера», «Культура»).

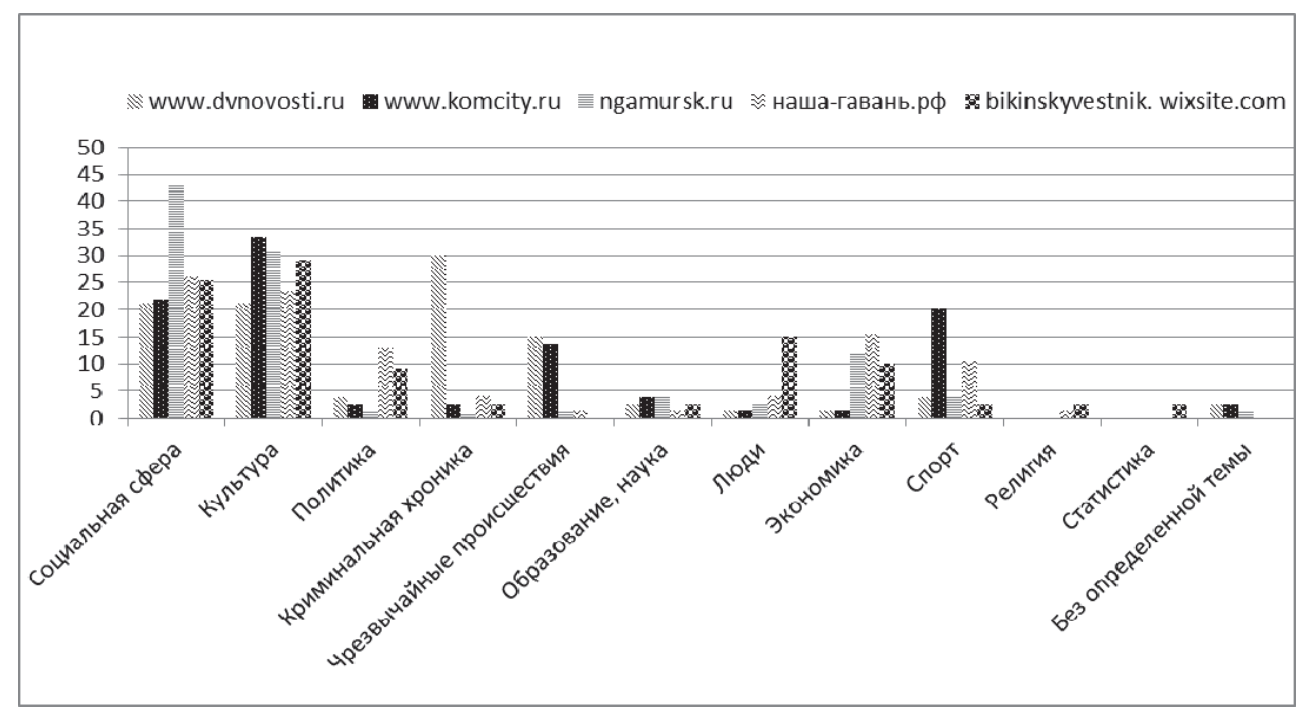

Рис. 1. Гистограмма процентного соотношения тем на каждом из ресурсов

На сайте www.komcity.ru наибольший объем занимают материалы из разделов «Культура», «Социальная сфера» и «Спорт» (33, 22 и 20 \% соответственно). Обзор чрезвычайных обстоятельств и происшествий занимает $14 \%$ из всех рассмотренных публикаций. Около $2 \%$ занимают разделы «Политика» и «Криминальная хроника». Примерно по 1 \% приходится на разделы «Люди» и «Экономика». Материалы без определённой темы занимают примерно 2 \%. Pecypc www.komcity.ru - дочерний проект редакции еженедельника «Наш город». Однако он не является копией печатного издания. Обновление новостной ленты происходит ежедневно, и в качестве публикуемой информации в первую очередь выступает обзор культурной жизни города. Также уделяется внимание социальной сфере и спортивным событиям. В связи с тем, что на обзор криминальной хроники приходится всего 2 \% от публикуемых материалов, частота публикаций на сайте www.komcity.ru ниже, чем на сайте www.dvnovosti.ru. 


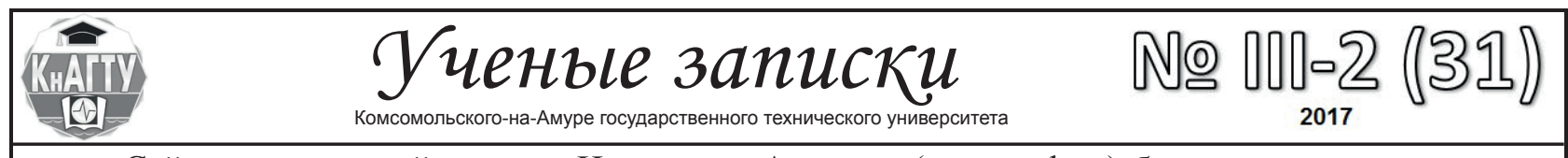

Сайт еженедельной газеты «Наш город Амурск» (ngamursk.ru) большое внимание уделяет освещению разделов «Социальная сфера», «Культура» и «Экономика» $(43,31$ и $12 \%$ соответственно). На материалы из категории «Образование, наука» приходится 4 \%. Около 1 \% занимает информация из разделов «Политика», «Чрезвычайные происшествия», «Криминальная хроника», а также публикации без определенной темы. На категорию «Люди» приходится 3 \% от общего объема публикаций. И на категорию «Спорт» приходится 4 \%. В печатном номере газеты вся сводка криминальных новостей публикуется в рамках под одним заголовком в рамках одной газетной статьи. Так как сайт дублирует информацию из еженедельника, на категорию «Криминальная хроника» приходится всего 1 \% от общего количества публикаций. Так как учредителем ресурса является администрация городского поселения «Город Амурск», основная ориентация сайта - обзор социальной и культурной сфер жизни города.

На сайте наша-гавань.рф основной объем публикуемой информации составляют материалы из разделов «Социальная сфера», «Культура», «Экономика» и «Политика» $(26,23,15$ и 13 \% соответственно). На этом сайте к категории «Социальная сфера» также были отнесены материалы об экологической обстановке, так как данная тема является актуальной для муниципального района, на который ориентирован сайт в первую очередь (Советско-Гаванский). На категорию «Спорт» приходится 10 \% публикаций. Тема «Люди» занимает 4 \%. Материалы из разделов «Чрезвычайные происшествия», «Образование, наука» и «Религия» занимают около 1 \% от общего объема информации. Сайт основной задачей ставит обзор наиболее острых социальных вопросов. Информация на портале обновляется ежедневно, но при этом в ленте новостей достаточно редко встречаются обзоры происшествий. Большое внимание уделяется публикациям об органах местного самоуправления.

Содержимое материалов на сайте bikinskyvestnik.wixsite.com дублирует информацию районной еженедельной газеты «Бикинский Вестник». Большая часть публикаций на этом ресурсе посвящена материалам из разделов «Культура» и «Социальная сфера» (29 и $25 \%$ соответственно). На данном сайте к разделу «Социальная сфера» были причислены также материалы из постоянной рубрики «А не пойти ли нам в гости», где дается информация о детях из детских домов. На раздел «Люди» приходится $15 \%$. Обзору экономической информации посвящено $10 \%$. Тема «Чрезвычайные происшествия» не освещается на ресурсе. Остальные темы занимают чуть больше 2 \%. Сводки криминальной хроники размещаются на сайте под единым заголовком ежемесячно. В преддверии Дня победы на сайте размещалось большое количество статей, посвященных участникам боевых действий. На сайте размещено достаточно большое количество статей общеознакомительного плана (польза рыбопродуктов, необходимость вакцинации). Кроме того, на данном сайте встречаются публикации статистических данных (средний уровень зарплат, количество людей, заболевших туберкулезом и т.п.)

Контент-анализ показал, что на территории Хабаровского края нет ресурса, который бы в полной мере освещал новости всех муниципальных единиц края. Наибольший охват территории осуществляется ресурсом www.dvnovosti.ru, который публикует новости г. Хабаровска, г. Комсомольска-на-Амуре и Еврейской автономной области. При этом все рассматриваемые ресурсы публикуют главные новости краевого и государственного масштаба. Обзор криминальных происшествий наиболее подробно и своевременно осуществляет только сайт www.dvnovosti.ru. Наименьший интерес ресурсы проявляют к разделам «Религия» и «Статистика». Основной объем публикуемой информации приходится на освещение событий социальной, культурной и политической сфер региона и края.

\section{ЛИТЕРАТУРА}

1. Информационное поле современной России: практики и эффекты / под ред. В. З. Гарифуллина // Материалы пятой Междунар. науч.-практ. конф., 16-18 окт. 2008 г. - Казань: Изд-во Казан. гос. ун-та, 2008. $288 \mathrm{c}$.

2. Демин, И. С. Поиск научной и учебной информации в сети Интернет / И. С. Демин // Вестник ТГУ. 2008. - № 9. - С. 446-450.

3. Паризер, Э. За стеной фильтров. Что Интернет скрывает от вас / Э. Паризер. - М.: Альпина Бизнес Букс, 2012. $-304 \mathrm{c}$. 